\title{
Age- and body mass index-related changes in cutaneous shear wave velocity
}

\author{
T. Hermanns-Lêe ${ }^{\mathrm{a}}$, F. Jonlet ${ }^{\mathrm{a}}$, A. Scheen ${ }^{\mathrm{b}}$, G.E. Piérard ${ }^{\mathrm{a}}$ \\ ${ }^{a}$ Department of Dermatopathology, University Medical Center Sart Tilman, B-4000 Liège, Belgium ${ }^{b}$ Department of Diabetes, Nutrition and \\ Metabolic Disorders, University Medical Center Sart Tilman, B-4000 Liège, Belgium
}

\begin{abstract}
Background: The in vivo visco-elastic characteristics of skin depend on a series of physiopatho-logical parameters. Among them, the age-related intrinsic tensile properties and the preconditioning of the tissues set under tension by the hypodermal volume might be of importance. Aims: To revisit the influence of age and body mass on the firmness and mechanical anisotropy of the skin as determined by the velocity of the shear wave propagation. Method: Resonance running time measurements (RRTM) were performed on the mid volar forearm in 110 adults of both sexes. In each subject 16 RRTM were collected at four different precise angles with regard to the limb axis. We recorded the lowest, the highest and the mean multidirectional RRTM as well as the coefficient of variation (CV) of the latter value. In addition, the body mass index (BMI) was calculated. Results: Age and BMI did not influence the minimum RRTM. In contrast, the maximum RRTM as well as the mean and $C V$ of the multidirectional RRTM, significantly rose in a progressively increasing proportion of the subjects older than 60 years. These changes were only encountered in subjects with a normal BMI ranging from 18 to 25. Sex-related differences were not disclosed. Conclusions: The intrinsic skin tension lines identified by the minimum RRTM are not significantly altered with age and BMI variations. In contrast, skin laxity identified by larger maximum and mean multidirectional RRTM may increase after 60 years of age in subjects with a normal BMI. This is accompanied by increased skin mechanical anisotropy identified by $C V$ values of the multidirectional RRTM over 40\%.
\end{abstract}

Keywords: Body mass index; Skin tension line; Skin anisotropy; Shear wave propagation

\section{Introduction}

The in vivo tensile strength of the skin depends on many physiopathological parameters and is influenced by a series of environmental variables. Age, sex, body site and fat accumulation in the hypodermis are known to be major factors involved in determining the mechanical and functional properties of skin at high stress (Piérard and Lapière, 1977; Marks, 1983; Henry et al., 1996; Piérard, 1999). These aspects have been studied so far using different instrumental methods based on distinct physical principles. Among them, the assessment of the velocity of elastic shear wave propagation represents a promising approach (Potts et al., 1983, 1984; Serup, 1985; Dorogi et al., 1986; Davis et al., 1989; Pereira et al., 1990; Mridha et al., 1992; McHugh et al., 1997; Enk et al., 1998; Vexler et al., 1999; Nizet et al., 2001). Indeed, the propagation of shear waves has been shown to change with age (Potts et al., 1983, 1984; Davis et al., 1989; Pereira et al., 1990). However, age below 65 years seemed to have no effect on this parameter (Vexler et al., 1999). From fundamental wave mechanics it is known that the propagation at the skin surface is likely to be influenced by several factors including the tissue thickness and the intrinsic mechanical properties of the skin and subcutaneous fat (Pereira et al., 1990; Vexler et al., 1999). Since each of these factors is likely change with age, it is not clear which observed changes in velocity are primarily due to structural alterations of the skin or due to body mass variations. The aim of the present study was to revisit the influence of age and body mass on the shear wave propagation in the skin.

\section{Volunteers and method}

A total of 110 adults of both sexes (74 women and 36 men), aged between 19 and 93 years were enrolled in the study. None of them suffered from a skin disorder. The body mass index $\left(\mathrm{BMI}=\right.$ weight/height $\left.{ }^{2}\right)$ was calculated.

Resonance running time measurements (RRTM) were performed using an advanced prototype named Reviscometer ${ }^{\circledR}$ RVM 600 (C + K Electronic, Cologne) (Nizet et al., 2001). The probe of the device contains two stylus sensors which are $2 \mathrm{~mm}$ apart. The pressure of the probe on the test material is controlled. When placed on the target site, one stylus transmits acoustic Shockwaves and the other acts as the receiver. The time the waves needs to travel from the transmitter to the receiver is the RRTM expressed in arbitrary units. The instrumental 
variability tested on human skin was lower than 14\% (Nizet et al., 2001) while it averaged to 1.2\% on a silicone gel.

Measurements were taken on apparently healthy skin on the mid volar forearm. A ring was affixed to the test site using double sided ring shaped stickers. It was marked with white dots placed at angles of $0^{\circ} / 180^{\circ}, 45^{\circ} / 225^{\circ}$, $90^{\circ} / 270^{\circ}$ and $135^{\circ} / 315^{\circ}$. The probe was also marked at a right angle to the alignment of the sensors. While placing the probe through the ring it was possible to take measurements in precise directions with steps of $45^{\circ}$ by adjusting the mark on the probe to one of the marks on the ring. In each subject, the angle $0^{\circ} / 180^{\circ}$ on the ring was oriented along the forearm axis. Four measurements were recorded in each of the four directions. The maximum and the minimum values of RRTM were recorded in each subject. In addition, the overall mean (M) of the 16 measures (multidirectional RRTM) and the corresponding coefficient of variation $\left(C V=10^{2} \mathrm{SD} \mathrm{M} \mathrm{M}^{-1}\right)$ were calculated for each subject. The percentiles 5 and 95 were calculated for each RRTM parameter in subjects lesser than 40 years of age. Such threshold values served to disclose specific variations linked to ageing.

\section{Results}

Age had no effect on the minimum RRTM (Fig. la). In contrast, both the maximum RRTM and the mean multidirectional RRTM showed a broader range of values with increasing age beyond 60 years (Fig. lb, c). At the same age, some individual multidirectional RRTM variability also increased over the percentile 95 calculated from younger individuals (Fig. 1d).

In our series of volunteers, the BMI values were uniformly distributed over seven decades of adult life (Fig. 2). Five slim subjects had a BMI lower than 18 and 33 overweight patients had their BMI over 25.

The minimum RRTM was not influenced by the BMI (Fig. 3a). A vast majority of the subjects showed a lack of influence of the BMI on the maximum RRTM and also on the mean and $C V$ of the multidirectional RRTM. However, some strikingly higher values of these three latter parameters were yielded in subjects within the normal range of BMI (Fig. 3b-d). None of the RRTM parameters seemed to be specifically affected by gender.

\section{Discussion}

The Reviscometer ${ }^{\circledR}$ is a new device for measuring the shear wave velocity in the skin (Nizet et al., 2001). The speed of propagation of the acoustic wave on the skin surface is inversely proportional to the stiffness and density of the tissues (Potts et al., 1983, 1984; Davis et al., 1989; Vexler et al., 1999). As a result, skin tension lines (Borges, 1984; Piérard and Lapière, 1987) influence RRTM (Nizet et al., 2001). The advantage of the Reviscometer ${ }^{\circledR}$ compared to other prototypes is the ease with which one can collect specific directional and also multidirectional RRTM, thus allowing the assessment of the skin tension lines (minimum RRTM), the firmness/laxity of skin (maximum RRTM), the average tensile strength (multidirectional RRTM) and mechanical anisotropy (RRTM coefficient of variation).

RRTM using the prototype are expressed in arbitrary units for technical reasons. Values given by such a device depend on several factors including the skin temperature, pressure of application of the probe, and feedback between the emitter and receiver sensors. Such variables can hardly be controlled and the given figures may vary among different probes. Hence, it is not scientifically possible to give real time measurements.

Reproducibility of the Reviscometer RRTM has been shown to be high with a coefficient of variation CV in the range of 6.7-13.6\% in unidirectional measurements on human skin (Nizet et al., 2001). Testing on silicone gel yielded higher reproducibility values with an average variability as low as $1.2 \%$.

Anisotropy of skin has been assessed previously in a normal biaxial system by calculating the ratio between the two values (Vexler et al., 1999). Such an evaluation is subjected to large intraindividual variations according to the orientation of the measurement (personal unpublished data). In the present study, $V$ of multidirectional RRTM in young adults reached an average of $22 \%$, thus indicating a discrete anisotropy in shear wave propagation. Such a phenomenon was previously reported using other devices (McHugh et al., 1997; Vexler et al., 1999) but was not found in another study (Pereira et al., 1990). The presently reported mechanical anisotropy was kept constant till about 60 years of age irrespective of the gender. Indeed the RRTM values in younger subjects showed little interindividual differences. This finding contrasts with a much wider range of variation in the tensile strength of the skin when assessed by the suction method. Precision of measurements and the relevance of the present parameters were unsurpassed by the previous reports. 
Fig. 1: Scatterplot of RRTM as a function of age in 110 adults: (a) The minimum RRTM indicating cutaneous tension lines is unchanged with age; (b) The maximum RRTM indicating the highest skin laxity increases in some subjects older than 60 years; (c) The mean multidirectional RRTM indicating the overall skin slackness increases in some subjects older than 60 years; and (d) The coefficient of variation $V$ of the multidirectional RRTM indicating skin mechanical anisotropy increases in some subjects older than 60 years.

Minimum RRTM

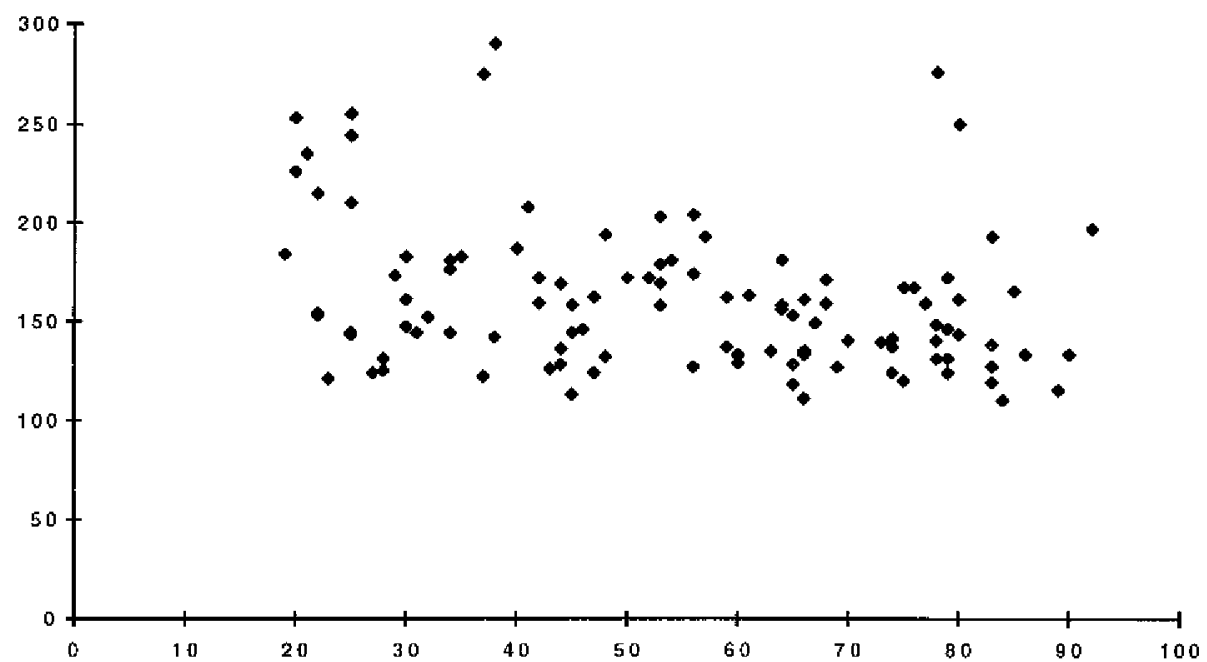

(a)

Age (year)

Maximum RRTM

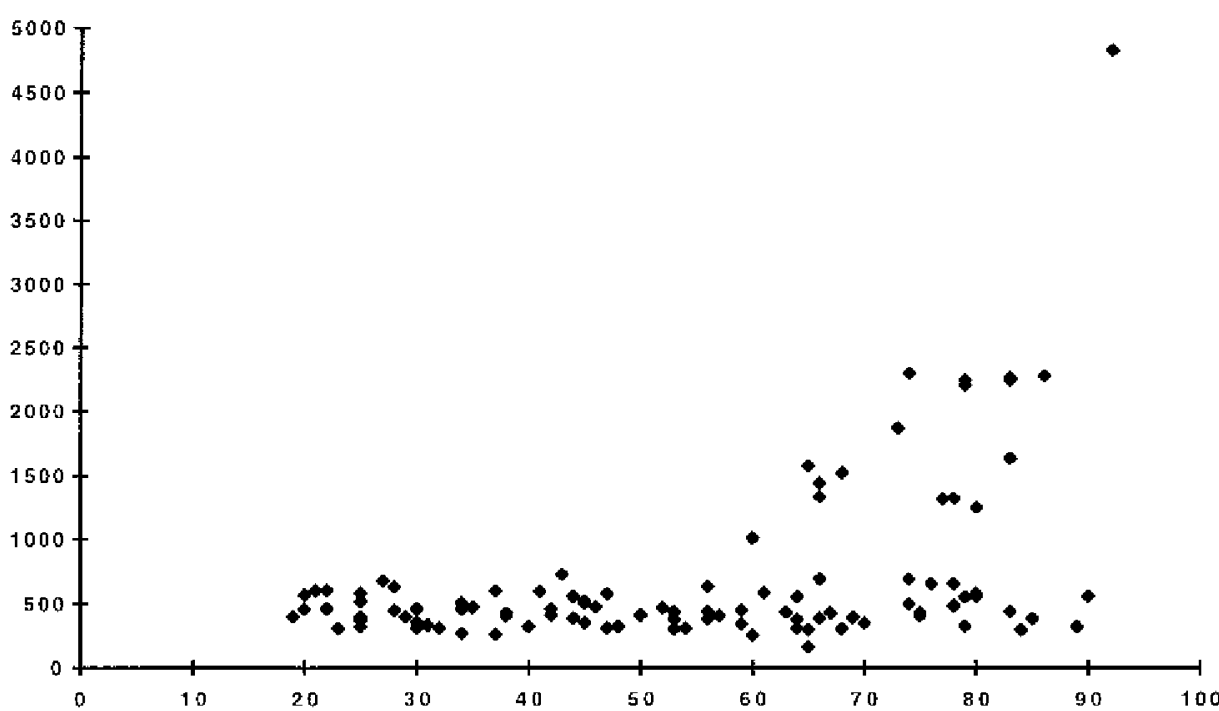

(b)

Age (year) 
Multidirectional RFTM

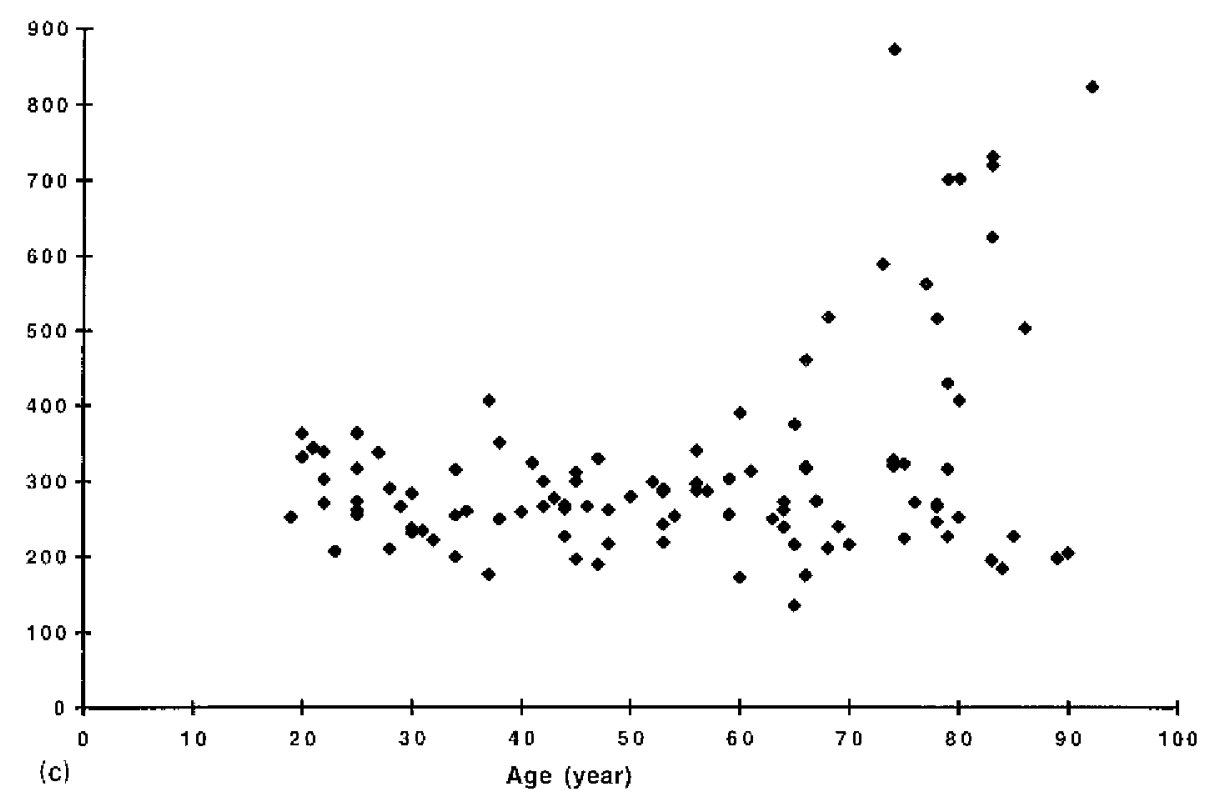

V RRTM $(\%)$

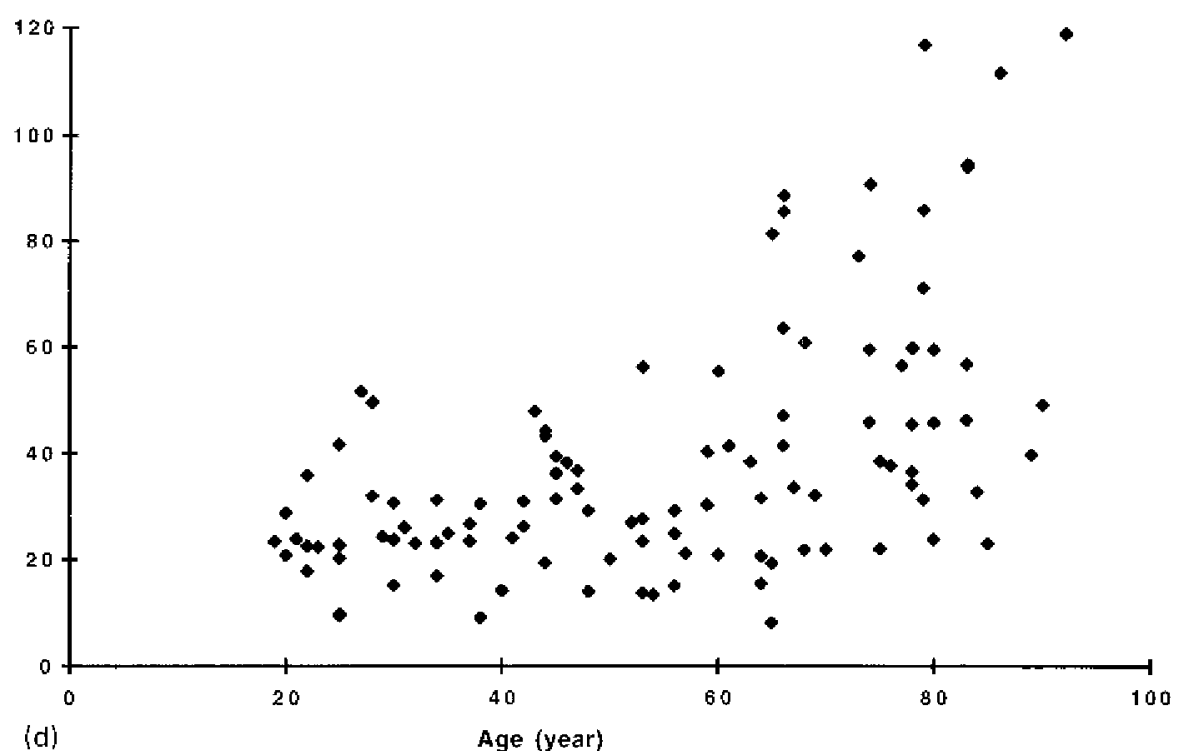

Fig. 1. (continued) 
Fig. 2: Uniform distribution of the BMI throughout the ages of the 110 adults.

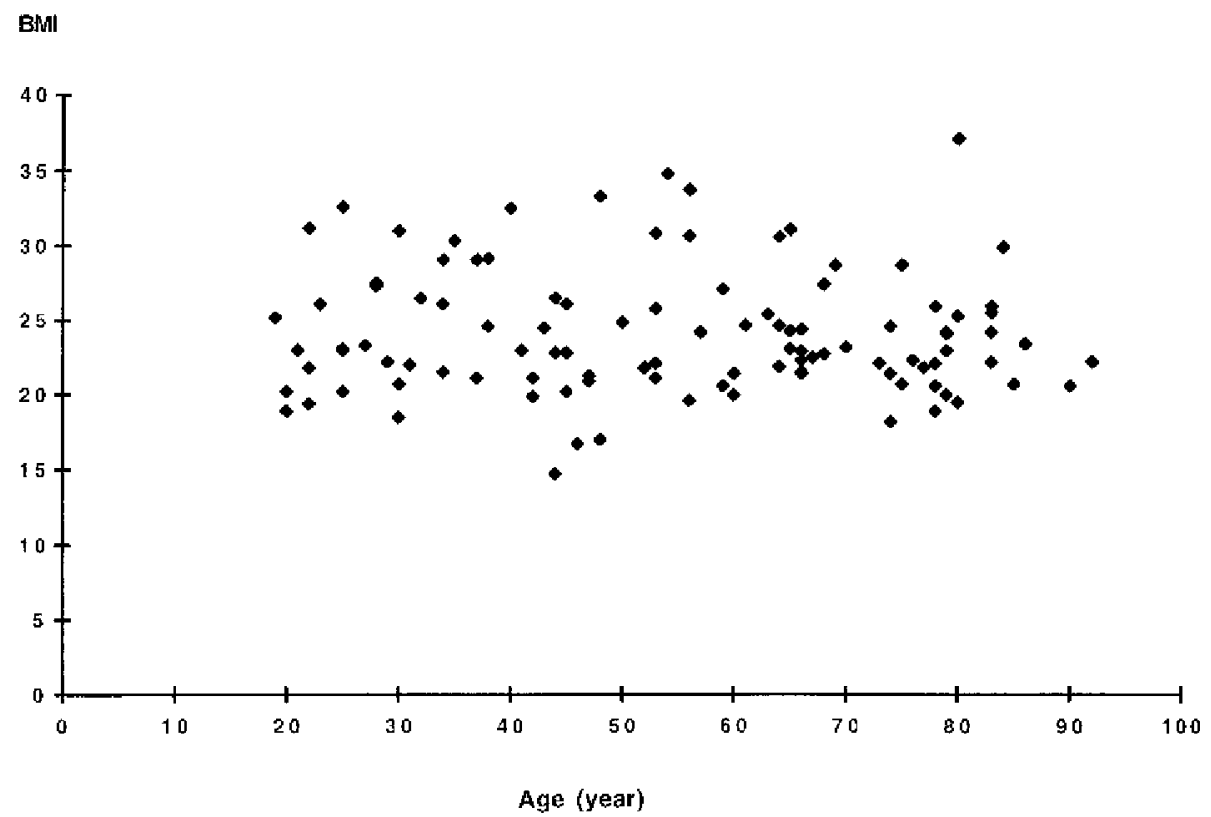

With increasing age a progressively larger proportion of the subjects exhibited higher values of maximum RRTM as well as mean and $C V$ of the multidirectional RRTM. This indicates a decreased firmness of the skin and an increased mechanical anisotropy, respectively. Hence, these subjects exhibited objective signs of cutaneous chronological ageing. There was obviously a wide range of interindividual differences in the severity of such manifestations of cutaneous ageing. These differences increased with the successive decades. Hence, evidence is provided for showing that skin slackness and mechanical anisotropy increase with age at different rates according to the individuals. The increased skin slackness with age was already shown using other physical principles for measuring the skin tensile strength even if some reports apparently provided the reverse information. The controversy is not closed (Piérard and Lapière, 1977; Daly and Odland, 1979; Lévêque et al., 1984; Robert et al., 1988; Escoffier et al., 1989; Lanir et al., 1993; Takema et al., 1994; Ishikawa et al., 1995; Piérard, 1999). The biological and physical reasons underlying such controversial aspects remain obscure. They have been previously addressed in the literature (Piérard et al., 1998; Piérard-Franchimont et al., 1998). Indeed, in a global view about ageing, the present data are in line with previous findings about altered shear wave propagation in bones (Wang et al., 1983; Chen and Saha, 1987).

The clinical experience indicates undoubtedly that the skin tensile strength may be different in slim and obese subjects. This was objectively measured in previous works (Piérard and Lapière, 1977; Ishikawa et al., 1995). The present data show that the minimum RRTM is almost unaffected by BMI. In contrast, the maximum RRTM, and the mean and $C V$ of the multidirectional RRTM may be considerably increased in some subjects in the normal BMI range. In our study this situation was encountered only in elderly subjects.

\section{Conclusion}

In conclusion, the intrinsic stiffness of the skin tensile lines as assessed by the minimum RRTM is not significantly affected by ageing and BMI. An increased skin slackness with increased values of the maximum and mean multidirectional RRTM occurs in an increasing proportion of older subjects in the normal BMI range Mechanical skin anisotropy is experienced by the same subjects. Measuring the shear wave velocity using a precise, and sensitive device can be a useful tool to objectively assess some specific aspects of ageing and its treatments. 
Fig. 3: Scatterplot of resonance running time measures as a function of the BMI in 110 adults: (a) The minimum RRTM indicating cutaneous tension lines is independent of the BMI; (b) The maximum RRTM indicating the highest skin laxity is increased in some subjects in the normal BMI range (18-25); (c) The mean multidirectional RRTM indicating the overall skin slackness is increased in some subjects in the normal BMI range (18-25); and (d) The coefficient of variation $V$ of the multidirectional RRTM indicating the skin mechanical anisotrophy is increased in some subjects in the normal BMI range (18-25).

\section{Minimum RRTM}

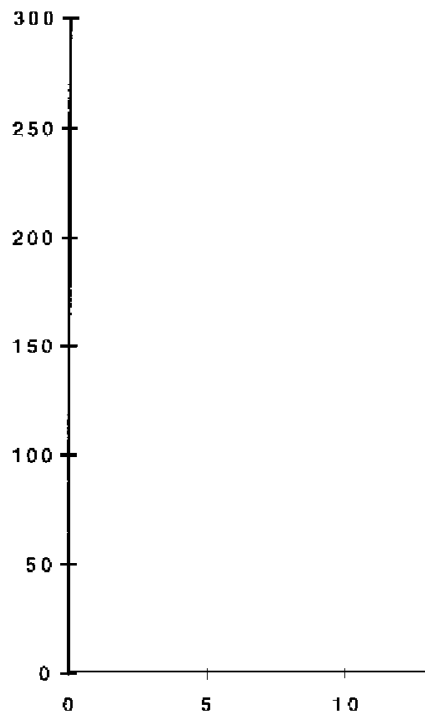

(a)

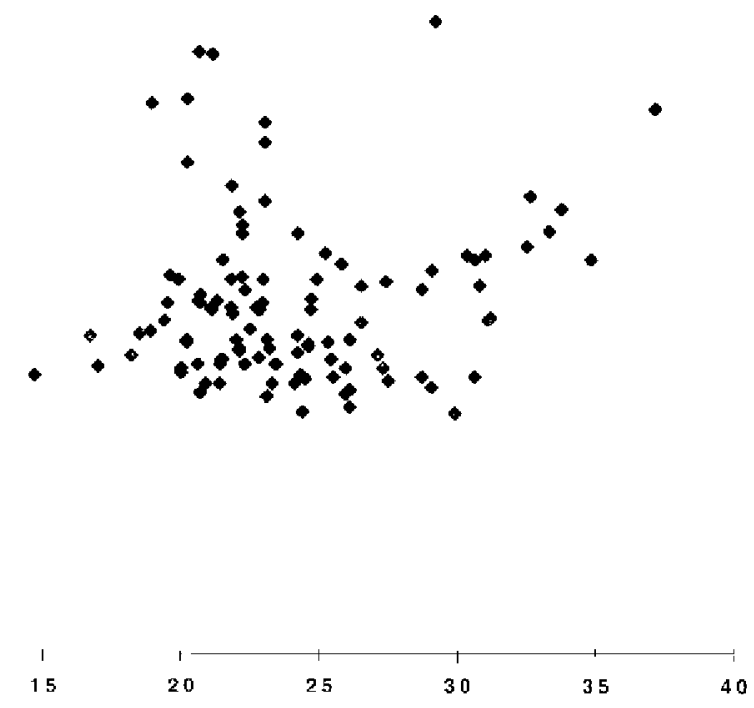

BNIII

Maximum RRTM

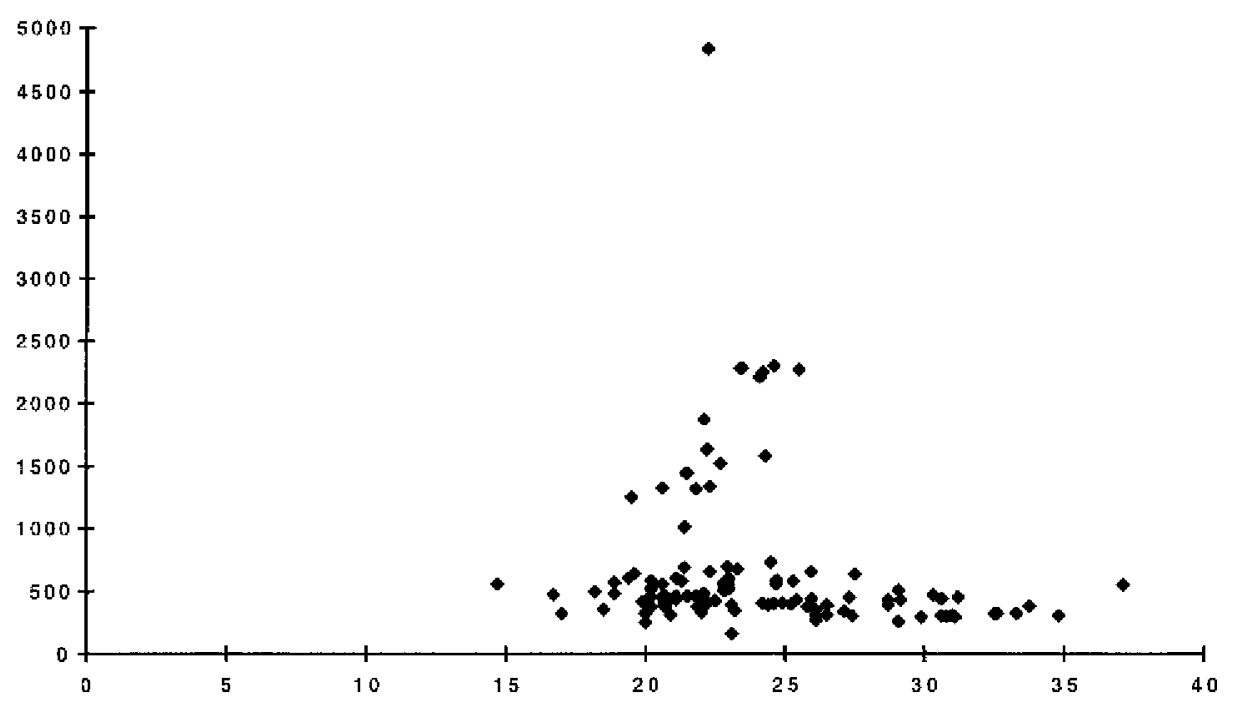

(b)

BMI 


\section{Multidirectional RRTM}

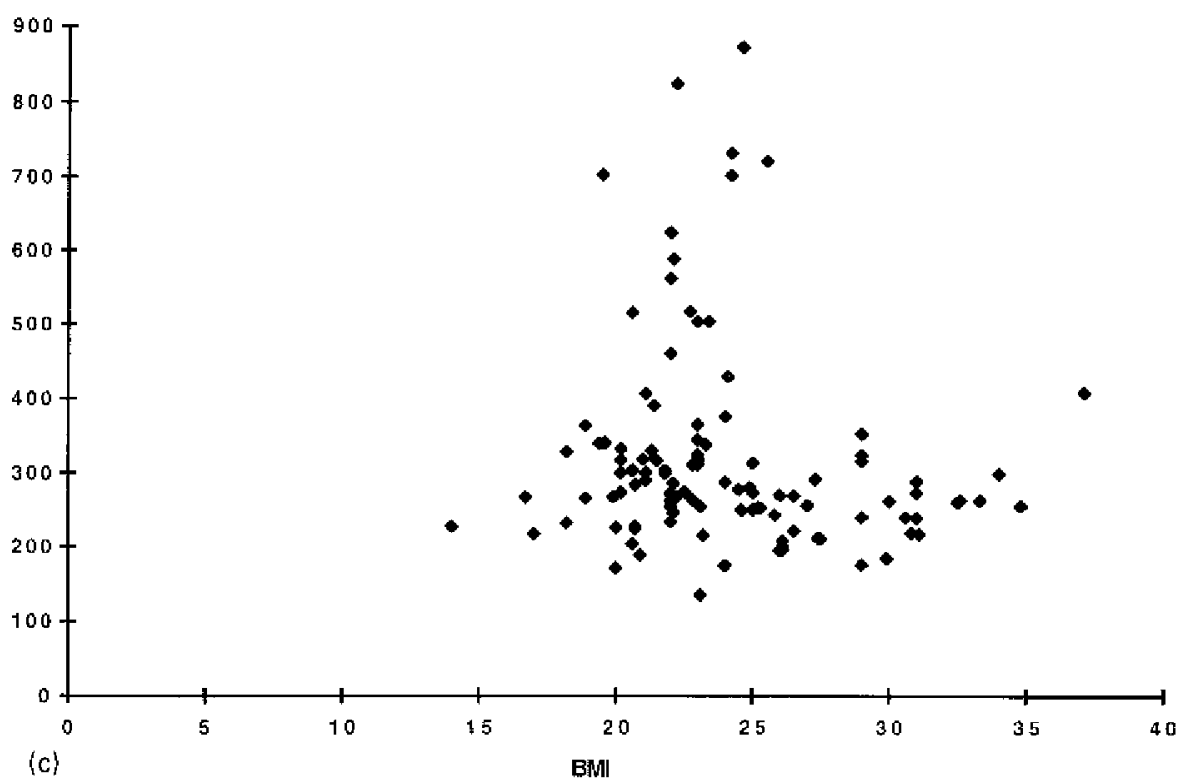

V RRTM (\%)

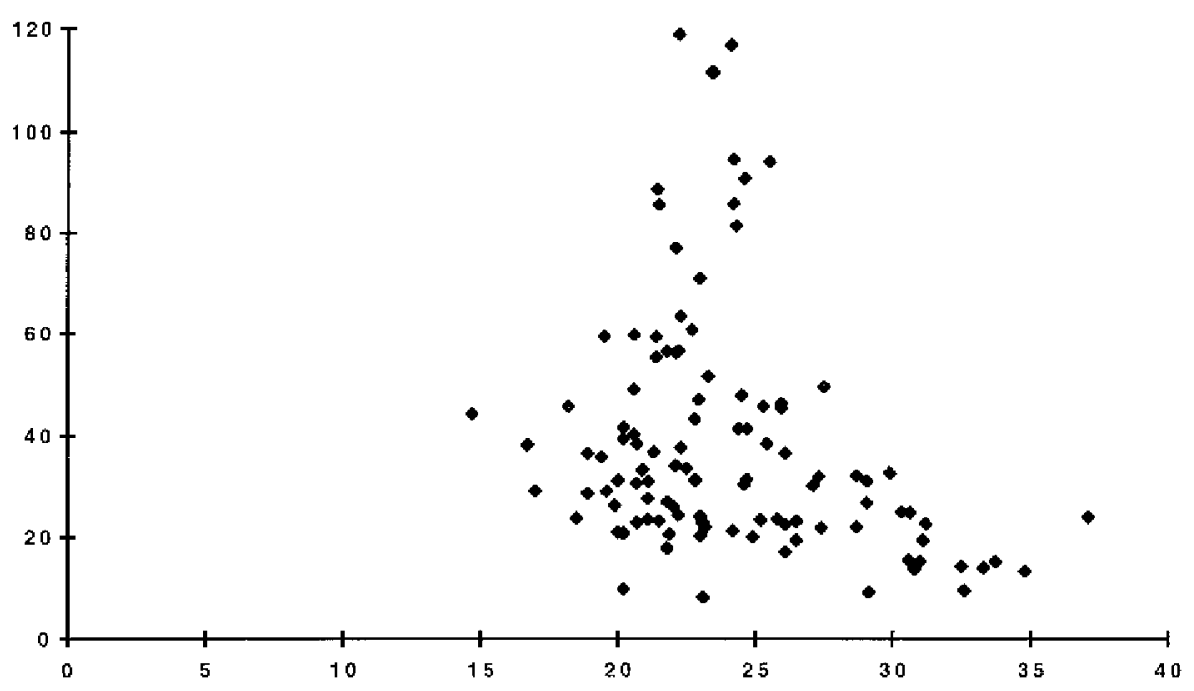

(d)

BNIII

Fig. 3. (continued)

\section{References}

Borges, A.F., 1984. Relaxed skin tension lines (RSTL) versus other skin lines. Plast. Reconstr. Surg. 73,144-150.

Chen, I.I.H., Saha, S., 1987. Wave propagation characteristics in long bones to diagnose osteoporosis. J. Biomech. 20, 523-527.

Daly, C.H., Odland, G.F., 1979. Age-related changes in the mechanical properties of human skin. J. Investig. Dermatol. 73, 84-87.

Davis, B.R., Bahniuk, E., Young, J.K., Barnard, C.M., Mansour, J.M., 1989. Age dependent changes in shear wave propagation through human skin. Exp. Gerontol. 24, 201-210.

Dorogi, P.L., DeWitt, G.M., Stone, B.R., Buras Jr., E.M., 1986. Viscoelastometry of skin in vivo using shear wave propagation. Bioengng. Skin 2, 59-70. 
Published in: Experimental Gerontology (2001), vol.36, iss.2, pp.363-372

Status: Postprint (Author's version)

Enk, CD., Elad, S., Vexler, A., Kapelushnik, J., Gorodetsky, R., Kirschbaum, M., 1998. Chronic graft-versus- host disease treated with UVB phototherapy. Bone Marrow Transplant. 22, 1179-1183.

Escoffier, C, De Rigal, J., Rochefort, A., Vasselet, R., Lévêque, J.L., Agache, P.G., 1989. Age-related mechanical properties of human skin: an in vivo study. J. Invest. Dermatol. 93, 353-357.

Henry, F., Van Look, R., Goffin, V., Fissette, J., Piérard, G.E., 1996. Mechanical properties of skin and liposuction. Dermatol. Surg. 22, 466-468

Ishikawa, T., Ishikawa, O., Miyachi, Y., 1995. Measurement of skin elastic properties with a new suction device. I-Relationship with age, sex and the degree of obesity in normal individuals. J. Dermatol. 22, 713-717.

Lanir, Y., Manny, V., Zlotogorski, A., Shafran, A., Dikstein, S., 1993. Influence of ageing on the in vivo mechanics of the skin. Skin Pharmacol. 6, 223-230.

Lévêque, J.L., Corcuff, P., De Rigal, J., Agache, P., 1984. In vivo studies of the evolution of physical properties of the human skin with age. Int. J. Dermatol. 23, 322-329.

Marks, R., 1983. Mechanical properties of the skin. In: Goldsmith, L.A. (Ed.). Biochemistry and Physiology of the Skin. Oxford University Press, New York, pp. 1237-1254

McHugh, A.A., Fowlkes, B.J., Maevsky, E.I., Smith, D.J., Rodriguez, J.L., Garner, W.L., 1997. Biochemical alterations in normal skin and hypertrophic scar after thermal injury. J. Burn Care Rehabil. 18, 101-108.

Mridha, M., Odman, S., Oberg, P.A., 1992. Mechanical pulse wave propagation in gel, normal and oedematous tissues. J. Biomech. 25, 1213-1218.

Nizet, J.L., Piérard-Franchimont, C, Piérard, G.E., 2001. Influence of the body posture and gravitational forces on shear wave propagation in the skin. Dermatology (in press).

Pereira, J.M., Mansour, J.M., Davis, B.R., 1990. Analysis of shear wave propagation in skin; application to an experimental procedure. J. Biomech. 23, 745-751.

Piérard, G.E., 1999. EEMCO guidance to the in vivo assessment of tensile functional properties of the skin. Part 1: relevance to the structures and ageing of the skin and subcutaneous tissues. Skin Pharmacol. Appl. Skin Physiol. 12, 352-362.

Piérard, G., Lapière, Ch.M., 1977. Physiopahtological variations in the mechanical properties of skin. Arch. Dermatol. Res. 260, 231-239.

Piérard, G.E., Lapière, Ch.M., 1987. Microanatomy of the dermis in relaxed skin tension lines and Langer's lines. Am. J. Dermatopathol. 9, 219-224.

Piérard, G.E., Henry, F., Castelli, D., Ries, G., 1998. Ageing and rheological properties of facial skin in women.

Gerontology 44, 159-161

Piérard-Franchimont, C, Castelli, D., Van Cromphaut, I., Bertin, C, Ries, G., Cauwenbergh, G., Piérard, G.E., 1998. Tensile properties and contours of aging facial skin. A controlled double-blind comparative study of the effects of retinol, melibiose-lactose and their association. Skin Res. Technol. 4, 237-243

Potts, R.O., Chrisman, D.A., Burns, E.M., 1983. The dynamic mechanical properties of human skin in vivo. J. Biomech. 16, 365-372.

Potts, R.O., Buras Jr., E.M., Chrisman, D.A., 1984. Changes with age in the moisture content of human skin. J. Investig. Dermatol. 82, 97100.

Robert, C, Blanc, M., Lesty, C, Dikstein, S., Robert, L., 1988. Study of skin ageing as a function of social and professional conditions: modification of the rheological parameters measured with a noninvasive method- indentometry. Gerontology 34, $284-290$.

Serup, J., 1985. Quantification of atorphy, telangiectasia and rebound dermatitis after topical corticosteroids. Methodlogical aspects. Bioengng. Skin 1, 271-277.

Takema, Y., Yorimoto, Y., Kawai, M., Imokawa, G., 1994. Age-related changes in the elastic properties and thickness of human facial skin. Br. J. Dermatol. 131, 641-648.

Vexler, A., Polyansky, I., Gorodetsky, R., 1999. Evaluation of skin viscoelasticity and anisotropy by measurement of speed of shear wave propagation with viscoelasticity skin analyzer. J. Investig. Dermatol. 113, 732-739.

Wang, F.H., Pal, S., Saha, S., 1983. The assessment of in vivo bone condition in humans by impact response measurement. J. Biomech. 16, 849-856. 